way in which the Grand Round has been advertised and organised, we have enabled greater learning opportunities for trainees.

\section{G387(P) VARIATIONS IN PAEDIATRIC TRAINING SATISFACTION- A NATIONAL TRAINING SURVEY EVALUATION}

${ }^{1} \mathrm{KS}$ Fan, ${ }^{2} \mathrm{HCK}$ Leung, ${ }^{3} \mathrm{KH}$ Fan, ${ }^{4} \mathrm{~J}$ Chan. ${ }^{1}$ Institute of Medical and Biomedical Education, St. George's, University of London, London, UK; ${ }^{2}$ Faculty of Medical Sciences, University College London, London, UK; ${ }^{3}$ Faculty of Medicine, Imperial College London, London, UK; ${ }^{4}$ Department of Cardiothoracic Surgery, University Hospital Coventry and Warwickshire, Coventry, UK

\subsection{6/archdischild-2020-rcpch.331}

Aims Paediatric medicine is straining under increasing demands. Training satisfaction and work conditions affect trainee recruitment and retainment. Annual training surveys by General Medical Council assess quality of training. We aimed to investigate variations in paediatric training satisfaction across the United Kingdom.

Methods Responses from national training survey of 20122019 were obtained from the General Medical Council website. Five trainee cohorts were included: Foundation Programme (F1/F2), General Practitioner (GP), Junior Paediatrics Trainee (ST1/ST2) and Paediatrics Registrar (SpR). All UK paediatric centres with at least four years of data were included and categorised by geographical region. Responses are analysed using analysis of variance.

Results The 2019 survey included 4650 paediatric trainees across 179 centres. The highest rated indicators were clinical supervision (90.49), clinical supervision(out of hours) (90.31) and education supervision (87.66) and lowest were workload (47.08), rota design (54.69) and study leave (61.00).

Trainees rotating through paediatrics (F1/F2/GP) report higher satisfaction than speciality trainees (both junior and registrars). Clinical supervision, clinical supervision (out of hours), workload, regional teaching and study leave varied significantly. Nationally, Northern Ireland (NI) ranked highest in 11 indicators, including overall satisfaction. All indicators varied significantly between various regions of the United Kingdom.

\begin{tabular}{|c|c|c|c|c|c|}
\hline \multicolumn{2}{|c|}{ Indicator (mean) } & \multirow{2}{*}{$\begin{array}{l}\text { 1st } \\
\text { F1/F2/GP (82.13) }\end{array}$} & \multirow{2}{*}{$\begin{array}{l}\text { 2nd } \\
\text { SpR (81.48) }\end{array}$} & \multirow{2}{*}{$\begin{array}{l}\text { 3rd } \\
\text { ST1/ST2 (80.65) }\end{array}$} & \multirow{2}{*}{$\begin{array}{l}\text { Variation } \\
P>0.05\end{array}$} \\
\hline Overall & Trainee & & & & \\
\hline $\begin{array}{l}\text { satisfaction } \\
(81.70)\end{array}$ & Region & NI (83.42) & Wales (82.74) & $\begin{array}{l}\text { South England } \\
(81.49)\end{array}$ & $P<0.05$ \\
\hline Workload & Trainee & $\mathrm{F} 1 / \mathrm{F} 2 / \mathrm{GP}(50.30)$ & SpR (43.36) & ST1/ST2(41.18) & $P<0.05$ \\
\hline$(47.08)$ & Region & Scotland (51.78) & Wales (51.31) & $\mathrm{NI}(46.97)$ & $P<0.05$ \\
\hline Study leave & Trainee & SpR (65.33) & ST1/ST2 (60.88) & F1/F2/GP (58.90) & $P<0.05$ \\
\hline$(61.00)$ & Region & NI (69.19) & Scotland (68.31) & $\begin{array}{l}\text { North England } \\
(65.72)\end{array}$ & $P<0.05$ \\
\hline Rota design & Trainee & F1/F2/GP (59.83) & SpR (57.46) & ST1/ST2 (56.20) & $P>0.05$ \\
\hline (58.63) & Region & Scotland (63.78) & Wales (60.89) & NI (58.07) & $P<0.05$ \\
\hline
\end{tabular}

Conclusion There are significant differences in satisfaction across training levels and regions in the United Kingdom. To improve staff wellbeing and patient outcomes, trusts should target low satisfaction rates based on national training survey.

\section{G388(P) WHO IS THAT PATIENT? A QUALITY IMPROVEMENT PROJECT TRYING TO ENSURE PAEDIATRIC SURGICAL PATIENTS ARE HANDED OVER TO THE WARD PAEDIATRICIANS}

${ }^{1} \mathrm{C}$ Strauss, ${ }^{2} \mathrm{R}$ Ajitsaria, ${ }^{1} \mathrm{~A}$ Taylor, ${ }^{1} \mathrm{H}$ Marshall, ${ }^{3} \mathrm{~N}$ Davey. ${ }^{1}$ Paediatrics, North Middlesex Hospital NHS Trust, London, UK; ${ }^{2}$ Paediatrics, Hillingdon Hospital, London, UK; ${ }^{3}$ Quality Improvement Clinic Ltd, UK

\subsection{6/archdischild-2020-rcpch.332}

Problem In our hospital, surgical patients under 16 are admitted to the paediatric ward under shared care. Unfortunately, surgical teams often don't inform the paediatric team of these admissions. This means that sick children can go unnoticed and untreated, as well as wider issues such as safeguarding being missed.

Aim By September 2019 all patients under the care of surgical teams, being admitted to the paediatric wards, will be handed over to the registrar covering the relevant ward.

Methods

Measurement The number of surgical patients admitted to a paediatric ward who are, or aren't, handed over to the ward registrar.

Interventions Three PDSA cycles were carried out with different interventions:

1. Emailing foundation doctors to request that they remind their teams to hand over patients.

2. Placing a reminder sticker on the front of paediatric clerking booklets

3. Moving the reminder to the end of the clerking where a plan is to be documented.

I had placed most of these booklets in our PAU however discovered that most of the patients were admitted through $\mathrm{A}$ $+\mathrm{E}$ where the booklets ran out.

3 b. I ensured there were plenty of stickered booklets in A $+\mathrm{E}$ and repeated the measurement.

Results Patients who weren't handed over received a score of 0 . Patients handed over by the surgical team received a score of 2 and patients handed over indirectly scored 1 .

\begin{tabular}{lll}
\multicolumn{2}{l}{ Abstract G388(P) } & Table 1 \\
\hline PDSA Cycle & Percentage Patients Handed Over (\%) & Mean Score \\
\hline Baseline & 16.5 & 0.3 \\
1 & 45.5 & 0.8 \\
2 & 30 & 0.45 \\
3 & 28.3 & 0.43 \\
$3 \mathrm{~b}$ & 38 & 0.77 \\
\hline
\end{tabular}

Conclusions and Reflections Despite some improvements the aim of this project was not met. Improving surgical handovers proved more difficult than predicted. Several simple interventions were trialed but had limited effect. The work has revealed issues which may require addressing, for example one surgical registrar didn't realise that paediatric patients were under joint care. Others did not complete a full clerking, thereby not reaching the handover reminder sticker at the end. This remains an important issue for patient safety. 